\title{
FUZZY ANALYTIC HIERARCHY BASED DBMS SELECTION IN TURKISH NATIONAL IDENTITY Card Management PRoject
}

\author{
F. Ozgur Catak, Servet Karabas, Serkan Yildirim \\ ${ }^{1}$ TUBITAK, National Research Institute of Electronics and Cryptology (UEKAE), \\ Gebze, Turkey \\ \{ozgur.catak, servet.karabas, serkan.yildirim\}@tubitak.gov.tr
}

\begin{abstract}
Database Management Systems (DBMS) play an important role to support enterprise application developments. Selection of the right DBMS is a crucial decision for software engineering process. This selection requires optimizing a number of criteria. Evaluation and selection of DBMS among several candidates tend to be very complex. It requires both quantitative and qualitative issues. Wrong selection of DBMS will have a negative effect on the development of enterprise application. It can turn out to be costly and adversely affect business process. The following study focuses on the evaluation of a multi criteria decision problem by the usage of fuzzy logic. We will demonstrate the methodological considerations regarding to group decision and fuzziness based on the DBMS selection problem. We developed a new Fuzzy AHP based decision model which is formulated and proposed to select a DBMS easily. In this decision model, first, main criteria and their sub criteria are determined for the evaluation. Then these criteria are weighted by pair-wise comparison, and then DBMS alternatives are evaluated by assigning a rating scale.
\end{abstract}

\section{KEYWORDS}

AHP, Fuzzy AHP, Fuzzy Logic, DBMS Selection, Multi Criteria Decision Making

\section{INTRODUCTION}

The selection of the Database Management System (DBMS) has been always been considered as a major source of uncertainty. The cost of purchasing and running DBMS efficiently is very high; therefore, DBMS selection is very crucial step for the software firms. DBMS software packages provide a large number of features that are customizable to meet specific needs of the organizations. Selecting a right DBMS to meet the organizational requirements is a difficult task. It needs a full examination of many factors. A questionnaire is used for determining the user preferences in software engineering process.

There has been a growth in the number of multiple-criteria decision-making (MCDM) methods to evaluate several alternatives to achieve a certain goal. The analytic hierarchy process (AHP) [1] is one of the most widely used methods. AHP method is a multi-criteria decision-making approach. The AHP method has attracted the interest of many decision makers to its ability to solve complex decision problems. It organizes the basic rationality by breaking down a problem into smaller constituents and then calls for only simple pairwise comparison judgments, to

DOI : 10.5121/ijist.2012.2403 
develop priorities in each level [2]. AHP decomposes a decision problem into a hierarchy of more easily comprehended sub-problems. The element of the hierarchy can relate to any aspect of the decision problem. Once the hierarchy is built, the decision makers evaluate its elements systematically by comparing them to other one, using two elements at a time [3].

In this article, evaluating DBMS alternatives is considered independently, because each DBMS solution is relatively different and independent. Pair-wise comparisons used in Fuzzy Analytical Hierarchy Process (FAHP) may result in errors or inconsistency if they are used with the preferences of Industry users or in all evaluations of DBMS selection process.

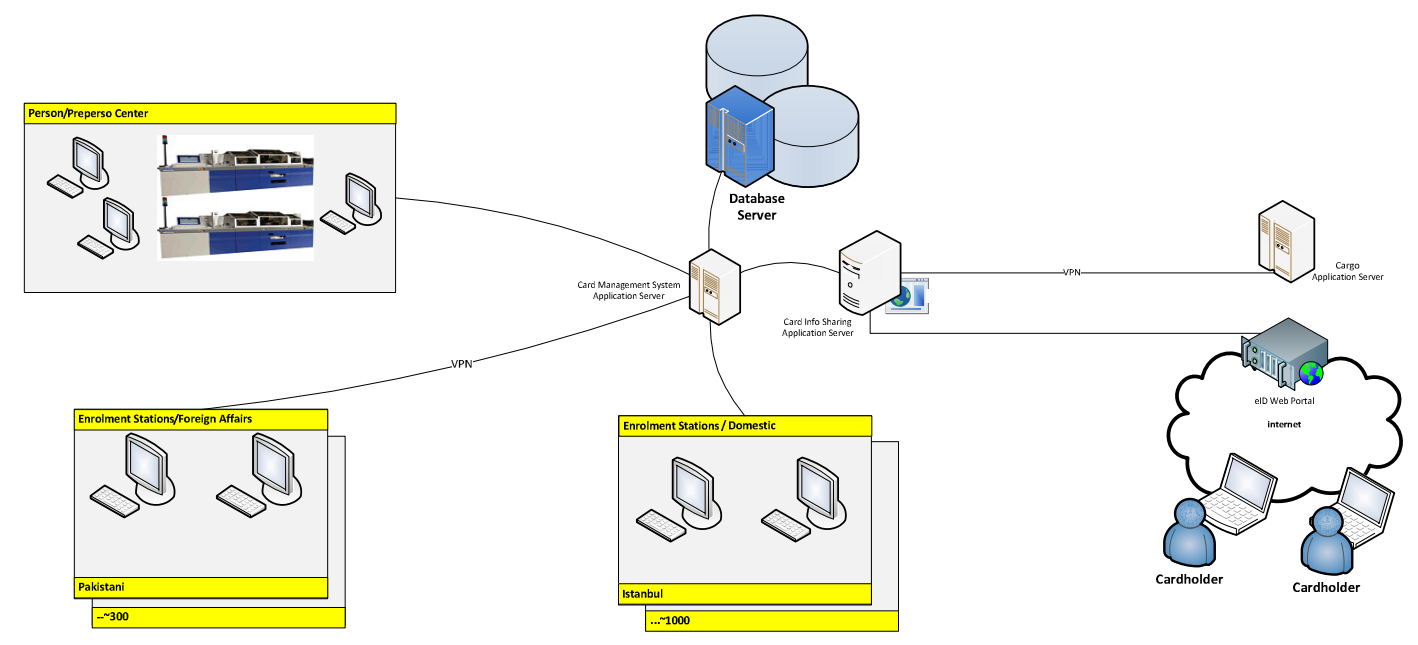

Figure 1. Turkish eID Management System Overview

The population of the Turkey is around 75 million people according to last census. The identification paper in Turkey is mandatory and every citizen required having an eID (electronic identity card). All signed operations related to card life cycle and data contained in the card occupy $40 \mathrm{~KB}$. The whole process for distributing eIDs to all citizens will be completed in three years. The selected DB for storing citizens' data must be able to manage/govern massive data block. At least three terminals in every district will have connections to the main server where services related to eID system are provided. Also, there will be total 3000 enrolment terminals connected and getting service from the main server. Moreover, every citizen who applied for an eID will be able to query the status of the eID by using a device called KIOSK. Based on all this information mentioned in the above sections, the selection of the database plays a crucial role in this research. The selection criterions are also a vital issue for the customer as well.

Proposed model is implemented for Turkish National Identity Card Management Project DBMS selection process of the Scientific and Technological Research Council of Turkey (TUBITAK), the leading agency for management, funding and conduct of research in Turkey. TUBITAK is responsible for promoting, developing, organizing, conducting and coordinating research and development in line with national targets and priorities. TUBITAK acts as an advisory agency to the Turkish Government on science and research issues, and is the secretariat of the Supreme Council for Science and Technology (SCST), the highest S\&T policy making body in Turkey. Analytic Hierarchy Process (AHP) and Fuzzy Analytic Hierarchy Process (Fuzzy AHP) are used to determine the relative weights of the attributes to evaluate DBMS selection in the National ID Card project. 
International Journal of Information Sciences and Techniques (IJIST) Vol.2, No.4, July 2012

\section{FUZZY ANALYTIC HIERARCHY PROCESS (FAHP)}

The FAHP method is an advanced analytical method which is developed from the AHP. In spite of the popularity of AHP, this method is often criticized for its inability to adequately handle the inherent uncertainty and imprecision associated with the mapping of the decision-maker's perception to exact numbers [4]. In FAHP method, the fuzzy comparison ratios are used to be able to tolerate vagueness. In literature, there are several methods to obtain the priorities. Xu's fuzzy least square method [5] is concerned with the question of estimation of weights of factors by least squares from a fuzzy judgment matrix. First, the expression form of least squares under fuzziness is given. Then the associated system of equation is developed. Buckley's geometric mean method [6], Chang's synthetic extend analysis [7], Mikhailov's fuzzy preference programming [8], Wang's two stage logarithmic programming [9]. One of the best known of these different methods is Fuzzy Extend Analysis proposed by Chang. Chang's fuzzy extend analysis is used in this research to evaluate the DBMS alternatives.

\section{A SIMPLIFIED DECISION MODEL FOR THE EVALUATION OF DBMSS}

In order to evaluate different Database Management Systems (DBMS), we developed a simplified decision model. Obviously, the simplification reduces the decision hierarchy. In this study, critical factors are grouped into eight main categories which are OS support, cluster capabilities, data size, table and view properties, database features, partitioning, backup and recovery and security. 27 sub criteria are taken to indicate the DBMS selection process. These are the independent variables of the decision model. It may also vary according to the business requirements of the enterprise information system. The critical factors used in our decision model are shown in Table 1.

Table 1. Critical factors used in DBMS Selection by Fuzzy AHP

\begin{tabular}{|c|c|c|}
\hline Criteria & Sub criteria & Description \\
\hline \multirow{4}{*}{$\begin{array}{l}\text { OS Support } \\
\quad(\mathrm{OS})\end{array}$} & Windows & \multirow[t]{4}{*}{ Operating systems supported } \\
\hline & Linux & \\
\hline & BSD & \\
\hline & Mac OS X & \\
\hline \multirow{3}{*}{$\begin{array}{l}\text { Cluster Support } \\
\text { (CLU) }\end{array}$} & Active-Active Cluster & \multirow[t]{3}{*}{ Supported cluster types } \\
\hline & Active-Passive Cluster & \\
\hline & Standby DB & \\
\hline \multirow{3}{*}{$\begin{array}{l}\text { Data Size } \\
\text { (DS) }\end{array}$} & Blob Data Size & \multirow[t]{3}{*}{ Max data size } \\
\hline & Row Length & \\
\hline & Max. Table Size & \\
\hline \multirow{2}{*}{$\begin{array}{l}\text { Table and } \\
\text { Views (TV) }\end{array}$} & Temporary Tables & \multirow[t]{2}{*}{ Supported table and view types } \\
\hline & Materialized Views & \\
\hline \multirow{3}{*}{$\begin{array}{c}\text { Database } \\
\text { Features } \\
\text { (FEAT) }\end{array}$} & Parallel Query & \multirow{3}{*}{ Supported database features } \\
\hline & Windowing & \\
\hline & $\begin{array}{l}\text { Automatic optimization SQL } \\
\text { Statements }\end{array}$ & \\
\hline \multirow{4}{*}{$\begin{array}{l}\text { Partitioning } \\
\text { (PART) }\end{array}$} & Range & \multirow[t]{4}{*}{ Supported partitioning types } \\
\hline & Hash & \\
\hline & List & \\
\hline & Shadow & \\
\hline
\end{tabular}


International Journal of Information Sciences and Techniques (IJIST) Vol.2, No.4, July 2012

\begin{tabular}{|c|l|l|}
\hline \multirow{3}{*}{$\begin{array}{c}\text { Backup and } \\
\text { Recovery } \\
(B R)\end{array}$} & Full Backup & \multirow{3}{*}{$\begin{array}{c}\text { Supported Backup and Recovery } \\
\text { types }\end{array}$} \\
\cline { 2 - 2 } & Incremental Backup & \\
\cline { 2 - 2 } & Partial Backup & \\
\hline \multirow{3}{*}{$\begin{array}{c}\text { Security } \\
\text { (SEC) }\end{array}$} & Online Backup & Security features of DBMS \\
\cline { 2 - 2 } & Brute Force Protection & \\
\cline { 2 - 2 } & Network Security & \\
\cline { 2 - 2 } & Password Complexity Rule & \\
\hline
\end{tabular}

\subsection{Extend Analysis Method on Fuzzy AHP}

For the estimation of the importance of these criteria, we used the FAHP. Let $\hat{A}$ represent a fuzzified reciprocal $w x h$ judgment matrix containing all pairwise comparisons $a_{i j}$ between elements $i$ and $j$ for all $i, j \in\{1,2, \ldots, n\}$.

$$
A=\left[\begin{array}{cccc}
(1,1,1) & a_{12} & \ldots & \tilde{a}_{1 n} \\
\tilde{a}_{21} & (1,1,1) & \ldots & \tilde{a}_{2 n} \\
\vdots & \vdots & \ddots & \vdots \\
\tilde{a}_{n 1} & \tilde{a}_{n 2} & \ldots & (1,1,1)
\end{array}\right]
$$

where $\tilde{a}_{j t}=\tilde{a}_{i j}{ }^{-1}$ and all are triangular fuzzy numbers(TFN) $\tilde{a}_{i j}=\left(l_{i j}, m_{i j}, u_{i j}\right)$ with $i_{i j}$ the lower and $u_{i j}$ the upper limit and $m_{i j}$ is the point where the membership function $\mu(x)=1$.

In the following, first the outlines of the extend analysis method on Fuzzy AHP are given and then the method is applied to a DBMS selection problem. Let $X=\left\{x_{1}, x_{2}, \ldots, x_{n}\right\}$ be object set, and $U=\left\{u_{1}, u_{2}, \ldots, u_{m}\right\}$ be a goal set. According to the method of Chang [7], each object is taken and analysis for each goal, $g_{i}$, is performed, respectively. Therefore, $\mathrm{m}$ extent analysis values for each object can be obtained, with the following signs:

$$
M_{g_{i}}^{1}, M_{g_{i}, \ldots,}^{2} M_{g_{i}}^{m} \quad i=1,2, \ldots, n
$$

where all the $(i=1,2, \ldots, m)$ are triangular fuzzy numbers whose parameters are represented as $(a, b, c)$, describing least, most and largest possible values respectively.

Step 1: The value of fuzzy synthetic extent with respect to the $i_{t h}$ object is defined as:

$s_{i}-\sum_{j=1}^{m} M_{\mathrm{Bi}_{i}}^{\mathrm{j}} \otimes\left[\sum_{\mathrm{i}=1}^{\mathrm{n}} \sum_{\mathrm{j}=1}^{\mathrm{m}} \mathrm{M}_{\mathrm{gi}}^{\mathrm{j}}\right]^{-1}$

to calculate $\sum_{j=1}^{m} M_{g_{i}}^{j}$ we perform the "fuzzy addition operation" of m extent analysis values for a particular matrix given in equation 2 below, at the last step of calculation, new $(l, m, u)$ set is obtained and used for the next:

$\sum_{j=1}^{m} M_{g_{\mathrm{i}}}^{j}=\left(\sum_{j=1}^{m} l_{j}, \sum_{j=1}^{m} m_{j} \sum_{j=1}^{m} n_{j}\right)$ 
where $l$ is the lower limit value, $m$ is the most promising value and $u$ is the upper limit value and to obtain the reciprocal in equation 1 , we perform the "fuzzy addition operation"

$\mathrm{M}_{\mathrm{g} i}^{\mathrm{j}}(\mathrm{j}=1,2, \ldots, \mathrm{m})$ values as given in equation 3 :

$\sum_{i=1}^{n} \sum_{j=1}^{m} M_{g_{i}}^{j}-\left(\sum_{j=1}^{m} l_{j}, \sum_{j=1}^{m} m_{j} \sum_{j=1}^{m} u_{j}\right)$

and then compute the inverse of the vector in the equation (3) to obtain equation (4):

$\left[\sum_{i=1}^{n} \sum_{j=1}^{m} M_{g_{i}}^{j}\right]^{-1}-\left(\frac{1}{\sum_{i=1}^{u} u_{i}}, \frac{1}{\sum_{i=1}^{u} m_{i}}, \frac{1}{\sum_{i=1}^{u} l_{i}}\right)$

Step 2: The degree of possibility of $M_{1} \geq M_{2}$ is defined as:

$V\left(M_{1} \geq M_{2}\right)=\operatorname{SUP}_{x y y}\left[\min \left(\mu_{M_{1}}(x), \mu_{M_{2}}(y)\right)\right]$

where SUP represents supremum and when a pair (x, y) exists such that $y \geq x$ and $\mu_{M_{1}}(x)=\mu_{M_{2}}(y)$ then we have $V\left(M_{2} \geq M_{1}\right)=1$. Given that $M_{1}$ and $M_{2} 2$ are convex fuzzy numbers, so $V\left(N_{1} \geq N_{2}\right)=1$ if $n_{11} \geq n_{21}$. And

$V\left(M_{2} \geq M_{1}\right)=\mu_{M_{2}}(d)=\left\{\begin{array}{cc}1 & 7 h_{2} \geq h_{1} \\ 0 & l_{1} \geq u_{2} \\ \frac{l_{1}-u_{2}}{\left(m_{2}-u_{2}\right)-\left(m_{1}-l_{1}\right)} & \text { otherwise }\end{array}\right.$

where $\mathrm{d}$ is the ordinate of the highest intersection point $D$ between $\mu_{M_{1}}$ and $\mu_{M_{2}}$. (See Figure 2)

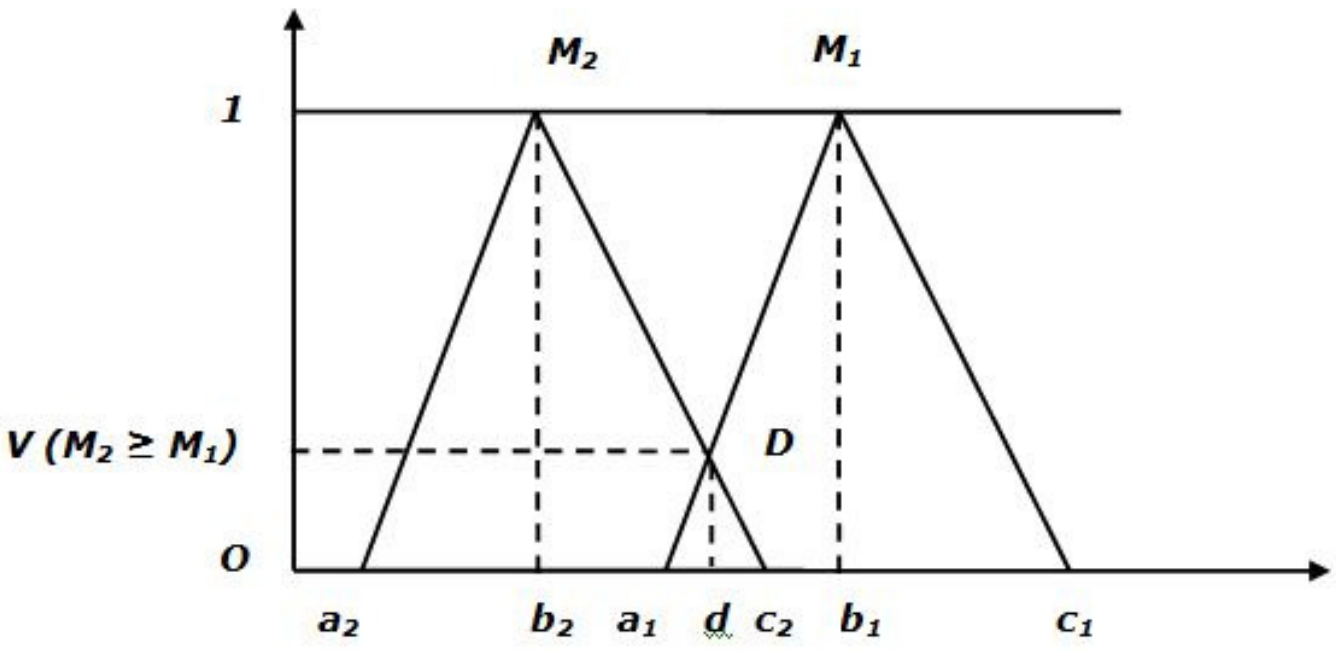

Figure 2. Intersection between $M_{1}$ and $M_{2}$ 
Step 3: The degree of possibility for a convex fuzzy number to be greater than $k$ convex fuzzy numbers $M_{i}(i=1,2, \ldots, k)$ can be defined by

$$
\begin{gathered}
V\left(M \geq M_{1}, M_{2}, \ldots, M_{k}\right)=V\left[\left(M \geq M_{1}\right) \text { and }\left(M \geq M_{2}\right) \text { and } \ldots \text { and }\left(M \geq M_{k}\right)\right] \\
=\min V\left(M \geq M_{i}\right), \quad i=1,2, \ldots, k
\end{gathered}
$$

assume that equation 7 is

$d^{\prime}\left(A_{i}\right)=\min V\left(S_{i} \geq S_{5}\right)$

For $k=1,2, \ldots, m, k \neq i$. Then the weight vector is obtained as follows

$W^{\prime}=\left(d^{\prime}\left(A_{1}\right), d^{\prime}\left(A_{2}\right), \ldots, d^{\prime}\left(A_{n}\right)\right)^{T}$

where $A_{i}(i=1,2, \ldots, n)$ are $n$ elements.

Step 4: After normalization, the normalized weight vectors are given in the equation 11

$W=\left(d\left(A_{1}\right), d\left(A_{2}\right), \ldots, d\left(A_{n}\right)\right)^{T}$

where $W$ is not a fuzzy number.

In this methodology, we have determined the criteria as given in Table 1. The fuzzy conversion scale is shown in Table 2. Different scales can be found in the literature as in Abdel-Kader and Dugdale's study.

Table 2 Triangular Fuzzy Conversion Scale

\begin{tabular}{|l|l|l|}
\hline Linguistic Scale & Triangular Fuzzy Scale & $\begin{array}{l}\text { Traingular Fuzzy } \\
\text { reciprocal Scale }\end{array}$ \\
\hline Just Equal & $(1,1,1)$ & $(1,1,1)$ \\
\hline Equally Important & $(1 / 2,1,3 / 2)$ & $(2 / 3,1,2)$ \\
\hline Weakly Important & $(1,3 / 2,2)$ & $(1 / 2,2 / 3,1)$ \\
\hline Strongly More Important & $(3 / 2,2,5 / 2)$ & $(2 / 5,1 / 2,2 / 3)$ \\
\hline Very strong more important & $(2,5 / 2,3)$ & $(1 / 3,2 / 5,1 / 2)$ \\
\hline Absolutely more important & $(5 / 2,3,7 / 2)$ & $(2 / 7,1 / 3,2 / 5)$ \\
\hline
\end{tabular}

\section{APPLICATION OF THE MODEL}

The proposed model is implemented for Turkish National Identity Card project's DBMS selection process of the Scientific and Technological Research Council of Turkey (TUBITAK), the leading agency for management, funding and conduct of research in Turkey. TUBITAK is responsible for promoting, developing, organizing, conducting and coordinating research and development in line with national targets and priorities. TUBITAK acts as an advisory agency to the Turkish Government on science and research issues, and is the secretariat of the Supreme Council for Science and Technology (SCST), the highest S\&T policy making body in Turkey. Fuzzy Analytic Hierarchy Process (Fuzzy AHP) is used to determine the relative weights of the attributes to evaluate DBMS selection in the Turkish National ID Card project. 
International Journal of Information Sciences and Techniques (IJIST) Vol.2, No.4, July 2012

Experts who are participating in the implementation of this model have regarded eight important criteria for DBMS selection. Table 3 shows the aggregated fuzzy pairwise comparisons of the four experts.

Table 3 Aggregated Fuzzy Comparison Matrix of the Attributes for Fuzzy AHP Model

\begin{tabular}{|l|c|c|c|c|c|c|c|c|}
\hline & OS & CLU & DS & TV & FEAT & PART & B\&R & SEC \\
\hline OS & $1,1,1$ & $0.29,0.3,0.4$ & $0.67,1,1.5$ & $0.67,1,1.5$ & $0.67,1,1.5$ & $0.7,1,1.5$ & $0.67,1,1.5$ & $1,1.33,2$ \\
\hline & & & & & & & & \\
CLU & $2.5,3,3.5$ & $1,1,1$ & $1.5,2,2.5$ & $1.5,2,2.5$ & $1.5,2,2.5$ & $1.5,2,2.5$ & $1.5,2,2.5$ & $1.5,2,2.5$ \\
\hline DS & $0.67,1,1.5$ & $0.4,0.5,0.67$ & $1,1,1$ & $1,1,1$ & $1,1,1$ & $0.4,0.5,0.7$ & $0.67,1,1.5$ & $0.67,1,1.5$ \\
\hline & & & & & & & & \\
TV & $0.67,1,1.5$ & $0.4,0.5,0.67$ & $1,1,1$ & $1,1,1$ & $0.4,0.5,0.7$ & $0.67,1,1.5$ & $1,1,1$ & $1,1,1$ \\
\hline & & & & & & & & \\
FEAT & $0.67,1,1.5$ & $0.4,0.5,0.67$ & $1,1,1$ & $1.5,2,2.5$ & $1,1,1$ & $1,1.33,2$ & $0.67,1,1.5$ & $1,1,1$ \\
\hline PART & $0.67,1,1.5$ & $0.4,0.5,0.67$ & $1.5,2,2.5$ & $0.67,1,1.5$ & $0.5,0.75,1$ & $1,1,1$ & $0.67,1,1.5$ & $1.5,2,2.5$ \\
\hline & & & & & & & & \\
BR & $0.67,1,1.5$ & $0.4,0.5,0.67$ & $0.67,1,1.5$ & $1,1,1$ & $0.67,1,1.5$ & $0.67,1,1.5$ & $1,1,1$ & $0.67,1,1.5$ \\
\hline SEC & $0.5,0.75,1$ & $0.4,0.5,0.67$ & $0.67,1,1.5$ & $1,1,1$ & $1,1,1$ & $0.4,0.5,0.7$ & $0.67,1,1.5$ & $1,1,1$ \\
\hline
\end{tabular}

Table 4 Aggregated Fuzzy Comparison Matrix of the Attributes for Fuzzy AHP Model

\begin{tabular}{|l|l|}
\hline$\sum_{i=1}^{8} M_{g \mathrm{i}}^{1}=(5.62,7.67,10.9)$ & $\sum_{i=1}^{8} M_{g \mathrm{i}}^{5}=(7.23,8.83,11.167)$ \\
\hline$\sum_{i=1}^{8} M_{g i}^{2}=(12.5,16,19.5)$ & $\sum_{i=1}^{8} M_{g i}^{6}=(6.9,9.25,12.167)$ \\
\hline$\sum_{i=1}^{8} M_{g \mathrm{i}}^{3}=(5.8,7,8.83)$ & $\sum_{i=1}^{8} M_{g \mathrm{i}}^{7}=(5.73,7.5,10.167)$ \\
\hline$\sum_{i=1}^{8} M_{g i}^{4}=(6.13,7,8.3)$ & $\sum_{i=1}^{8} M_{g i}^{8}=(5.63,6.75,8.3)$ \\
\hline
\end{tabular}

Aggregated fuzzy comparison matrix of the attributes for our fuzzy decision model is show in Table 4.

The degree of possibility of superiority is calculated and is denoted by $V\left(M_{i} \geq M_{j}\right)$. The calculated values are show in Table 5 . 
International Journal of Information Sciences and Techniques (IJIST) Vol.2, No.4, July 2012

Table 5 Degree of Possibility of Superiority

\begin{tabular}{|c|c|c|c|}
\hline$V\left(M_{1} \geq M_{2}\right)-0,32$ & $V\left(M_{2} \geq M_{1}\right)-0,91$ & $V\left(M_{5} \geq M_{1}\right)-1$ & $V\left(N_{7} \geq M_{1}\right)-0.90$ \\
\hline$V\left(M_{1} \geq M_{2}\right)=1$ & $V\left(M_{2} \geq M_{2}\right)=0,-3$ & $V\left(M_{5} \geq M_{2}\right)=0,374$ & $V\left(M_{7} \geq M_{2}\right)=0,262$ \\
\hline$V\left(M_{1} \geq M_{4}\right)=1$ & $V\left(M_{2} \geq M_{4}\right)=1$ & $V\left(M_{5} \geq M_{3}\right)=1$ & $V\left(M_{7} \geq M_{2}\right)=1$ \\
\hline$V\left(M_{1} \geq M_{0}\right)=0,87$ & $V\left(M_{n} \geq M_{5}\right)=0.75$ & $V\left(M_{5} \geq M_{1}\right)=1$ & $V\left(N_{-} \geq M_{1}\right)=1$ \\
\hline$V\left(M_{1} \geq M_{3}\right)=0,84$ & $V\left(M_{2} \geq M_{6}\right)=0.72$ & $V\left(N_{5} \geq M_{0}\right)=0.954$ & $V\left(N_{5} \geq M_{5}\right)=0,843$ \\
\hline$V\left(M_{1} \geq M_{7}\right)=1$ & $V\left(M_{2} \backslash g e M_{7}\right)=0.93$ & $V\left(M_{5} \geq M_{7}\right)=1$ & $V\left(N_{7} \geq M_{5}\right)=0,801$ \\
\hline$V\left(M_{1} \geq M_{0}\right)=1$ & $V\left(M_{2} \geq M_{0}\right)=1$ & $V\left(M_{5} \geq M_{0}\right)=1$ & $V\left(M_{7} \geq M_{0}\right)=1$ \\
\hline$V\left(M_{2} \geq M_{1}\right)=1$ & $V\left(M_{2} \geq M_{1}\right)=0,91$ & $V\left(M_{6} \geq M_{1}\right)=1$ & $V\left(M_{2} \geq M_{1}\right)=0,869$ \\
\hline$V\left(M_{2} \geq M_{2}\right)=1$ & $V\left(M_{4} \geq M_{2}\right)=0,073$ & $V\left(M_{3} \geq M_{2}\right)=0.451$ & $V\left(M_{2} \geq M_{2}\right)=0,071$ \\
\hline$V\left(M_{2} \geq M_{4}\right)=1$ & $V\left(M_{4} \geq M_{2}\right)=1$ & $V\left(M_{6} \geq M_{7}\right)=1$ & $V\left(M_{g} \geq M_{n}\right)=0,959$ \\
\hline$V\left(M_{2} \geq M_{5}\right)=1$ & $V\left(M_{4} \geq M_{5}\right)=0,72$ & $V\left(M_{3} \geq M_{A}\right)=1$ & $V\left(N_{8} \geq M_{4}\right)=0,95 \varepsilon$ \\
\hline$V\left(M_{2} \geq M_{3}\right)=1$ & $V\left(M_{4} \geq M_{6}\right)=0,693$ & $V\left(M_{6} \geq M_{5}\right)=1$ & $V\left(M_{g} \geq M_{5}\right)=0,699$ \\
\hline$V\left(M_{2} \geq M_{7}\right)=1$ & $V\left(M_{4} \geq M_{7}\right)=0,923$ & $V\left(M_{3} \geq M_{7}\right)=1$ & $V\left(M_{0} \geq M_{3}\right)=0,671$ \\
\hline$V\left(M_{2} \geq M_{2}\right)=1$ & $V\left(M_{4} \geq M_{0}\right)=1$ & $V\left(M_{6} \geq M_{g}\right)=1$ & $V\left(M_{9} \geq M_{7}\right)=0,009$ \\
\hline
\end{tabular}

The minimum degree of possibility of superiority for each criterion over another is calculated. The weight vector is given as

$W=(0.3214,1,0.1299,0.0734,0.3741,0.4509,0.2624,0.0716)$.

The normalized weight vector is calculated as

$W=(0.1198,03726,0.0484,0.0274,0.1394,0.1680,0.098,00267)$.

The normalized weight of each criterion is shown in Figure 3.

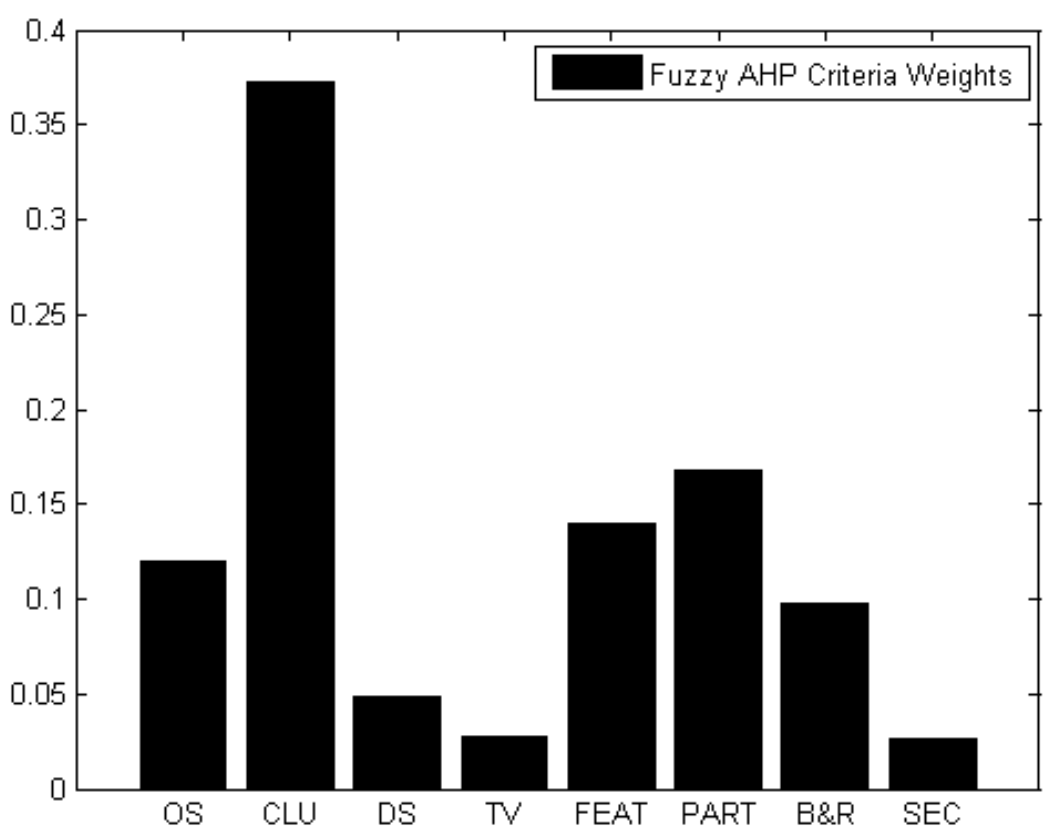

Figure 3. Weights of criteria used in DBMS Selection Model

Figure 4 shows the graphical representation of fuzzy priority numbers calculated from Fuzzy AHP pair wise comparison. 


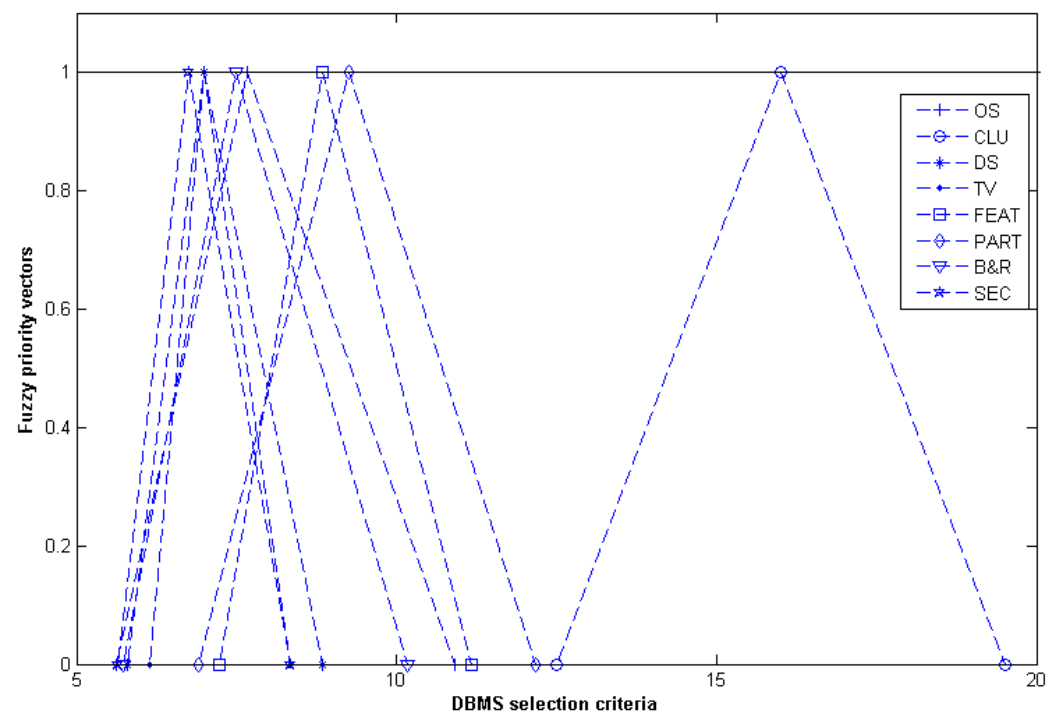

Figure 4. Fuzzy Membership Functions for DBMS Selection Features

\section{Conclusions}

The aim of this study is to investigate the application of the Fuzzy Analytic Hierarchy Process (FAHP) method of multi-criteria decision-making within a DBMS selection problem. The AHP provides an effective approach for solving multiple criteria decision making problems in software development. This case study shows, that although the selection of the database management system selection - is one of the most important activities of an IT project in a company in an IT project-, it does not mean it has to be complicated. An algorithm using Fuzzy AHP is emphasized and proposed as an original study of DBMS. Fuzzy AHP is utilized in order to eliminate or reduce cognitive biases in decision making. The developed model eases the decision maker's mission of choosing the quantitative weights and making further calculations.

\section{ACKNOWLEDGEMENTS}

We would like to thank specially to Muhammet Yildiz, Osman Davulcu, Dr. Ahmet Fatih Mustacoglu, Dr. Oktay Adalier, Emrah Yagmurlu, Yusuf Kurt, Gokhan Yildiz, Asiye Bozkurt Kilic and Tugce Ozkaptan, the members of the Turkish National ID Card project, for their support and help in structuring this study.

\section{REFERENCES}

[1] Saaty, T.L.(1980)" The Analytic Hierarchy Process", McGraw Hill,.

[2] Saaty, T.L (1986) "Axiomatic Foundation of the Analytic Hierarchy Process", Management Sciences, Vol. 32, No. 7, pp 841-855.

[3] Saaty, Thomas L., (2008) "Relative Measurement and its Generalization in Decision Making." Review of the Royal Spanish Academy Of Sciences, Mathematics. Vol. 6, No 2, pps. 251-318.

[4] Deng, H, (1999). "Multicriteria analysis with fuzzy pairwise comparisons". International Journal of Approximate Reasoning. Vol. 21, pp. 215-231.

[5] Xu, R.,(2000) "Fuzzy least square priority method in the analytic hierarchy process", Fuzzy Sets and Systems. pp. 395-404. 
[6] Buckley, J.J.,(1985) Fuzzy hierarchical analysis, "Fuzzy Sets and Systems”. Vol 17,No 3, pp. 233247.

[7] Chang, Da-Yong., (1996) “Applications of the extent analysis method on fuzzy AHP”, European Journal of Operational Research. Vol.3, pp 95.

[8] Mikhailov, L., (2003) "Deriving priorities from fuzzy pairwise comparison judgments", Fuzzy Sets and Systems. Vol. 134, No. 3, pps. 365-385.

[9] Wang, Y.M., Yang, J.B. and Xu, D.L., (2005) "A two-stage logarithmic goal programming method for generating weights from interval comparison matrices”, Fuzzy Sets Systems. Vol. 152, pp. 475498.

[10] Saaty, Thomas L. and Vargas, Luis Gonzalez, (2001).Models, methods, concepts \& applications of the analytic hierarchy process, Massachusetts : Kluwer Academic Publisher, ISBN 0-7923-7267-0.

[11] Tama, Maggie C.Y. and Tummalab V.M. Rao. (2001) "An application of the AHP in vendor selection of a telecommunications system", The International Journal of Management Science. Vol.29.

[12] Balaban, Erdal and Sharma, Sushil K. (2009) "A Framework of ERP System Selection by an Analytic Hierarchy Process Approach”, ISDSI 2009 Decision Sciences in Global Enterprise Management

[13] Boroushaki, S. and Malczewski, J., (2008) "Implementing an extension of the analytical hierarchy process using ordered weighted averaging operators with fuzzy quantifiers in ArcGIS", Computers \& Geosciences, pp. 399-410.

[14] Saaty, Thomas L. (1989) "How to make a decision: The Analytic Hierarchy Process", European Journal of Operational Research. Vol 48, No 9.

[15] Wimmer, Maria, Codagnone, Cristiano and Janssen, Marijn, (2008) "Future e-government research: 13 research themes identified in the eGovRTD2020 project"

\section{Authors}

F. Ozgur Catak(ozgur.catak@tubitak.gov.tr) is a senior researcher at TUBITAK BILGEM. He received his B.Sc. degree in Electrical/Electronics Engineering from Eskisehir Osmangazi University, Turkey, in July 2001, He received his M.S. from Istanbul Bilgi University, in 2008. He is a Ph.D. candidate in Informatics, Istanbul University. His main scientific interest concentrates on machine learning, cloud computing, stochastic optimization, mathematical modelling.

Servet Karabas(servet.karabas@tubitak.gov.tr) is a project manager at TUBITAK BILGEM. He received a B.Sc.in Electronic Engineering from Uludag University in 1996 and M.Sc. in Computer Engineering from Gebze Institude of Technology in 2000. His main scientific interest concentrates on key management systems, electronic identity solutions.

Serkan Yildirim(serkan.yildirim@tubitak.gov.tr) is a senior researcher at TUBITAK BILGEM. He received his B.Sc. degree in Computer Engineering from Marmara University, Turkey. He received his M.Sc. in Computer Engineering from Marmara University. His main scientific interest concentrates on software engineering, distributed computing.
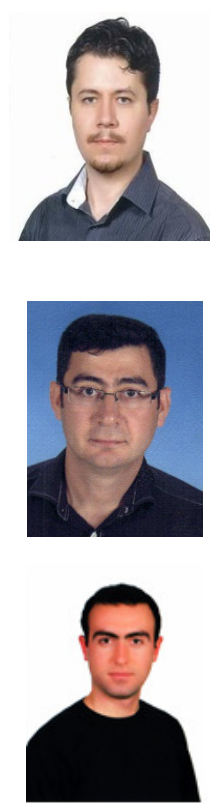